\title{
A CONSTRUÇÃO DE UM MODELO CURRICULAR PARA A EDUCAÇÃO FÍSICA A PARTIR DO COTIDIANO ESCOLAR: POSSIBILIDADES DE UM PROJETO DE EXTENSÃO
}

\author{
THE CONSTRUCTION OF A MODEL CURRICULUM FOR PHYSICAL \\ EDUCATION FROM THE SCHOOL ROUTINE: POSSIBILITY OF AN EXTENSION \\ PROJECT
}

\author{
Marina F. de S. Antunes ${ }^{1}$ \\ Gislene Alves do Amaral ${ }^{2}$
}

\begin{abstract}
RESUMO
Este artigo descreve o projeto de extensão desenvolvido no âmbito da formação continuada de professores de Educação Física da Rede Municipal de Ensino de Uberlândia. Objetiva contribuir com a formação continuada de professores das escolas públicas de Uberlândia, por meio do estudo de suas práticas docentes para a construção de um modelo curricular para a educação física escolar. Esta iniciativa se junta a outras ações que já foram e/ou estão sendo desenvolvidas por professores das Universidades com a finalidade de ampliar os espaços de formação continuada, bem como as alternativas para o envolvimento e a organização coletiva dos profissionais das escolas públicas, na busca da transformação da prática educativa, além de estreitar os laços entre universidade e escolas públicas, por meio de projetos de extensão.
\end{abstract}

Palavras-chave: Educação física escolar. Currículo em educação física. Extensão universitária

\begin{abstract}
This article describes the extension project developed under the continuous training of physical education teachers of municipal schools in Uberlândia. Aims to contribute to the continuing education of teachers in public schools in Uberlândia, through the study of their teaching practices to build a model of curriculum for physical education. This initiative joins other actions that have been and/or are being developed for teachers of universities in order to enlarge the area of continuing education, as well as alternatives to the involvement and collective organization of professionals in the public schools, in the pursuit of transformation of educational practice, and to strengthen the ties between university and public schools through outreach projects.
\end{abstract}

Key-words: School physical education. Curriculum in physical education. University extension.

\section{O “chão que pisamos”: pressupostos teóricos}

A necessidade de recolocar a prática pedagógica como centro da reflexão nos processos de formação continuada tem provocado o surgimento de experiências de parcerias Universidade/Escola, em diversos estados do país. A fertilidade destas experiências tem contribuído para aproximar estes dois espaços de produção de

\footnotetext{
${ }^{1}$ FAEFI / NUTESES / Universidade Federal de Uberlândia - UFU. E-mail: marina@ faefi.ufu.br

${ }^{2}$ FAEFI / NUTESES / Universidade Federal de Uberlândia - UFU. E-mail: giamaral@,faefi.ufu.br
} 
conhecimento, tornando possível o diálogo entre pesquisadores da academia e professores/pesquisadores da educação básica. Apresentamos neste artigo uma experiência de curso de extensão que encontra-se nessa direção.

Por meio desse curso trazemos algumas contribuições à produção de currículo na Educação Física Escolar de acordo com o referencial teórico metodológico que vem sendo construído com um grupo de professores da Rede Municipal de Ensino da cidade de Uberlândia. A finalidade é apontar possibilidades de materialização de um planejamento de currículo numa perspectiva crítica de educação, cujos aspectos centrais são a participação dos professores da educação básica na definição dos rumos traçados e a busca de uma concepção de formação humana ampliada que se sustente na reflexão sobre a prática pedagógica (AMARAL, 2003).

O estudo de alternativas para transformar o planejamento do trabalho pedagógico em educação física à luz da pedagogia e das teorias críticas em educação e educação física tornou-se um dos grandes desafios enfrentado em diferentes contextos e por diversos autores e atores desde a década de 1990. Neste processo, busca-se responder à necessidade de colocar as experiências de ensino como eixo central do trabalho coletivo e tomá-las como objeto de reflexão, superando as lacunas que surgiram no que podemos chamar de transição da denuncia para a proposição.

Este trabalho descreve o projeto de extensão desenvolvido desde 2007, com a finalidade de contribuir com a formação continuada de professores de educação física, por meio do estudo de suas práticas docentes para a construção de novas estratégias de ensino, bem como de materiais curriculares voltados para a ampliação das possibilidades de tratamento dos elementos da cultura corporal, tidos como temas de ensino (o jogo, os esportes, a expressão corporal, as danças, as lutas e a ginástica).

Esse projeto ofereceu 100 vagas anuais, com carga horária de 60 horas, distribuídas ao longo do período letivo, levando em consideração o calendário escolar das escolas municipais. Foi oferecido no espaço de formação continuada que a Secretaria de Educação do Município propicia, ressaltando que desde 1997 foi feita uma organização desse espaço de maneira que, uma vez por mês, os professores tem um espaço/tempo para a formação continuada. Neste dia eles não ministram aulas nas escolas municipais. No entanto, como não é obrigatória a participação, nem todos participam desse momento.

Este grupo de formação continuada existe desde 1996, tendo passado por diferentes momentos políticos, enfrentando as mais variadas dificuldades, sendo, portanto, 
fundamental destacar que o trabalho em construção é resultado de movimentos de conflitos, de lutas, de rupturas, enfim, características que, embora não possam ser aqui explicitadas, foram fundamentais para os rumos assumidos pelo grupo que persistiu até este momento envolvido com esta produção. Além disso, em função do longo tempo de existência, não se pode também desconsiderar, como mais um elemento condicionante, as entradas e saídas constantes de professores no grupo, exigindo, assim, um esforço permanente para a manutenção do caráter coletivo, pela necessidade de aproximação dos que chegam e de paciência pedagógica dos antigos, permitindo, assim, que se recriassem as condições de igualdade garantindo a participação.

Embora não seja possível, no espaço deste artigo, contextualizar toda trajetória coletiva do grupo de formação continuada e os caminhos que resultaram na incorporação de determinados referenciais teóricos, é importante ressaltar que, neste percurso foram sendo construídas alternativas para a sistematização do planejamento a partir de um instrumental próprio que foi denominado Estratégias de Ensino. Salientamos que, para esse grupo de professores, estratégia de ensino é entendida como o planejamento de uma sequência de aulas para o desenvolvimento de um determinado tema, visando alcançar os objetivos propostos em termos de apropriação do conhecimento instrumental, social e comunicativo pelos alunos (KUNZ, 2001a).

É necessário destacar também que nesta trajetória temos procurado enfrentar o desafio de superar algumas das dificuldades em relação ao diálogo que os professores podem, e devem, ter com as produções acadêmicas. Esta preocupação já vem sendo apontada por pesquisadores da área da Educação Física que discutiram, durante toda a década de 1990, as lacunas nesse diálogo, seja por interpretações distorcidas ou enviesadas, seja pelo distanciamento entre algumas produções e o cotidiano escolar, ou ainda por uma série de outros fatores (CAPARRÓZ, 2001).

Trabalhando com professores de escolas públicas ao longo dos últimos anos identificamos que a organização do trabalho pedagógico, a seleção de conteúdos e o trato com o conhecimento científico continuam sendo os maiores problemas enfrentados pela grande maioria dos profissionais da área (Kunz, 2001b).

Isto pode ser explicado pelo fato de que na área da educação física, a formação docente está permeada por uma cultura com forte influência do diagnóstico, da normatização e da objetividade; ou da racionalidade técnica (MOLINA NETO; MOLINA, 2003; HILDEBRANDT-STRAMANN, 2003; SOARES et al., 2012). Os currículos ainda 
encontram-se ancorados num paradigma técnico-linear, marcados por disciplinas com práticas voltadas para o conhecimento técnico/desportivo, em detrimento das disciplinas da área do conhecimento humanista; sendo que estas últimas precedem as primeiras; numa perspectiva de que a teoria precede, ou deve preceder a prática; visão que contribui para a desarticulação entre teoria e prática e, por conseguinte, para a fragmentação do conhecimento.

Na medida em que avançamos com o curso de extensão, constituindo momentos de efetiva produção coletiva, foram sendo elaborados alguns instrumentos de planejamento, os quais estão sendo utilizados como ferramentas para transformação tanto do próprio ato de planejar, como do processo de ensinar. Acreditamos que este caminho se encontra na direção do que Schneider (2000) aponta como consequências do que se tem chamado de planejamento colaborativo, no qual os participantes atuam com seu saber próprio para organizar seus problemas, ideias, ideais e seu conhecimento da realidade e, ao fazerem isso, criam automaticamente o novo, em proveito de todos e com trabalho organizado.

Neste percurso, foi necessário nos debruçarmos, repetidas vezes, e por diferentes caminhos, sobre o estudo dos pressupostos da perspectiva histórico/cultural, buscando romper com uma visão cristalizada em nosso meio, na qual o desenvolvimento humano seria um processo de atualização de capacidades já potencialmente dadas desde o nascimento, dependentes apenas do aspecto maturacional; ou ainda um processo de aquisições acumulativas hierarquicamente organizadas, configurando um repertório que se amplia de forma gradual e linear.

Em contraposição a esta visão, temos procurado incorporar nas reflexões e decisões acerca do currículo a compreensão de que não é possível pensar em desenvolvimento humano fora das condições concretas de vida, organizadas, por sua vez, segundo particularidades culturais (ROCHA, 2005). Neste sentido, torna-se necessário superar dicotomias que, do ponto de vista das perspectivas naturalistas e/ou funcionalistas, nos impuseram uma leitura fragmentada do sujeito, pensado no sentido das polarizações entre: social x biológico; interno x externo; cultural x individual; psíquico x material; cognitivo x motor.

Por outro lado, esta possível superação não pode ser entendida apenas como a necessidade de uma suposta "integração" ou "soma" destes elementos, pois a fragmentação se manteria como condição implícita no momento de pensar condições para o estabelecimento destas relações. 
No caminho para a construção de uma nova leitura sobre quem é o ser humano e como ele se constitui, encontramos Severino (2009), segundo o qual a existência humana só se efetiva pela mediação do agir histórico/social, de tal forma que os diferentes modos de "ser humano" decorrem das diferentes formas de agir constituídas historicamente, sendo, portanto, a prática a essência deste existir.

O existir é, antes de tudo desdobrar-se pelo agir numa interação permanente e intensa com os dados da natureza material, com os outros sujeitos na sociedade e com as construções simbólicas, subjetivamente produzidas por sua consciência e guardadas na memória e objetivamente conservadas pela cultura (SEVERINO, 2009, p. 44).

A compreensão de como se configura a existência humana, na perspectiva deste autor, se completa com a introdução do conceito de tridimensionalidade. As raízes dessa leitura podem ser encontradas, do ponto de vista filosófico, na explicação materialista sobre a origem da consciência humana como dimensão da subjetividade que

[...] emerge como uma função plenamente integrada aos processos das atividades que os homens passaram a desenvolver para cuidar da própria sobrevivência material. [...] É por isso também que pensamento e ação se misturam e se vinculam em suas origens (SEVERINO, 2007, p. 33).

Dessa explicação depreende-se a presença de três categorias que efetivam as mediações da existência humana: o trabalho, a linguagem e o poder. Em seu percurso de relações mediadas o homem vai se constituindo e conservando sua existência concreta na medida em que se relaciona com a natureza (prática produtiva) com os outros (prática política) e consigo mesmo (prática simbólica). Por isso a utilização da expressão "tridimensional" por Severino (2007 e 2009) para explicar a constituição do ser histórico/cultural.

Nessa mesma direção, Aranha (2006) elabora uma explicação sobre o processo de produção da cultura como resultado dessa capacidade do homem agir sobre a natureza e sobre si mesmo, por meio da atividade chamada trabalho. Nesse processo tornou-se, ainda, capaz de reproduzir atividades de outros homens e inventar novas, tomando sua própria ação como fonte de ideias, o que a autora chama de "experiência humana".

As relações que os homens estabelecem entre si para produzir a cultura se dão em diversos níveis que não se excluem, mas se complementam e se interpenetram. Apenas por questões didáticas costumamos separar e distinguir essas relações em: relações de trabalho, [...] relações políticas, $[\ldots]$ e relações culturais [...] (p. 17). 
Estas reflexões, na medida em que dialogam com a prática pedagógica, ao longo do projeto, nos conduziram a um movimento constante de formular novas perguntas que, por sua vez exigiam novos estudos, permitindo o "retorno" à prática pedagógica, num processo de realimentação do currículo, ou de uma curricularidade, pensada como movimento permanente. Esse tem sido, para nós, um interessante exercício de consolidação da prática pedagógica, cujas justificativas são reconstruídas na medida em que aprofundamos o estudo de fundamentos filosófico/pedagógicos, buscando responder as problematizações advindas do cotidiano.

A constante revisão dos referenciais teóricos nos permite chegar a momentos de síntese, como este, nos quais a prática pedagógica indica as contribuições da teoria, para sua compreensão e/ou transformação, e não o contrário. Além disso, estas reflexões devem conduzir a compreensão de como o conhecimento deve ser organizado, na forma de saberes escolares produzidos de forma autônoma e não copiados ou reproduzidos a partir de currículos impostos ou programas prontos.

\section{O curso de extensão em educação física escolar: os caminhos percorridos, as possibilidades de construção de um modelo curricular}

$\mathrm{Na}$ primeira versão do curso de extensão, trabalhamos com a sistematização de saberes escolares em um modelo de planejamento. O referido curso foi planejado objetivando revitalizar o espaço de formação continuada para professores de educação física das escolas públicas de Uberlândia, a partir do Centro Municipal de Estudos e Projetos Educacionais - CEMEPE; promover a vivência e a reflexão sobre estratégias de ensino construídas no contexto escolar, tomando-as como objeto de estudo para compreender os fundamentos teórico/metodológicos que as sustentam e refletir sobre a produção de saberes escolares na educação física, à luz de uma análise sobre qual é seu objeto de ensino e suas relações com o conhecimento.

Sua implementação deu-se a partir da discussão de três aspectos da prática pedagógica: 1- Reprodução, modificação e criação de estratégias de ensino; 2- A produção de saberes escolares; 3- Organização dos saberes escolares no currículo. Como meta foi proposto: a) Constituir um ambiente de trabalho coletivo, orientado pelos princípios do diálogo crítico e da discutibilidade irrestrita, no qual os professores sintam-se confortáveis para experimentar, questionar e criar novas metodologias de trabalho; b) estimular os professores participantes do curso a se envolverem na organização do trabalho coletivo em 
seus ambientes escolares; c) Ampliar a participação de docentes da Faculdade de Educação Física, em espaços de formação continuada, buscando minimizar o distanciamento entre o espaço da pesquisa e o cotidiano escolar.

Como resultado deste primeiro curso identificamos que as contribuições dos autores estudados forneceram elementos teóricos para que o coletivo de professores, no contexto citado, pudesse repensar questões sobre: o que, como, por que e para que ensinar educação física na escola; cooperando para aproximar a prática pedagógica do grupo de referenciais mais críticos, na medida em que o grupo foi se apropriando de uma compreensão materialista de existência e, por conseguinte de formação humana.

Posteriormente, seguindo o mesmo formato do ano anterior, elaboramos um curso que teve como tema a "Organização dos conteúdos de ensino" na estrutura microcurricular (relacionada ao componente curricular educação física).

Sua implementação se deu a partir da discussão de aspectos relacionados com o modelo de planejamento que vem sendo experimentado nesse contexto de formação continuada. Este curso foi desenvolvido com o objetivo de promover a sistematização e socialização de estratégias de ensino, com a finalidade de ampliar a compreensão dos fundamentos teórico/metodológicos que as sustentam; planejar a prática pedagógica numa perspectiva ampliada de formação orientada pelas dimensões produtiva, simbolizadora e social do conhecimento humano (Severino, 2009); refletir sobre a produção de saberes escolares na educação física, com a finalidade de organizar a microcurricularidade e elaborar o Plano Anual da área, o qual foi elaborado ao final do curso.

A dinâmica de trabalho proposta foi: 1) Construção da microcurricularidade real a partir dos eixos temáticos definidos no curso anterior, contemplando cada zona de desenvolvimento da educação básica e as estratégias de ensino já sistematizadas; 2) Estudo dos fundamentos da aprendizagem humana; 3 ) Elaboração e socialização de estratégias de ensino; 4) Sistematização do plano anual da educação física, que serviu de guia para o planejamento do ano seguinte.

Naquela oportunidade destacou-se o seguinte em relação ao planejamento de ensino: qualquer que seja a opção metodológica, sempre haverá limites, aspecto que requer sua constante reavaliação e/ou reformulação, buscando o atendimento das necessidades do grupo considerando, inclusive, sua heterogeneidade, e que a pretensa criticidade de um professor não está contida no "modelo" ou instrumentos que ele "utiliza" para planejar. Antes, deve ser buscada na prática cotidiana, na forma como lida com os alunos, com os 
saberes, na maneira como materializa princípios éticos, dentro e fora da sala de aula. Não estávamos com isso negando a necessidade do "modelo", mas reafirmando que a transformação da realidade educacional exige apreender como o "modelo" foi construído e com que visão de mundo, esta última entendida como processo dialético de interpretação da realidade (AMARAL, et al., 2009).

Para o curso seguinte nosso intuito foi enfatizar o tema "Sistematização da Prática Pedagógica" com a finalidade de legitimar o espaço de formação continuada conquistado, garantindo um ambiente de trabalho coletivo, orientado pelos princípios do diálogo crítico e da discutibilidade irrestrita, no qual os professores sintam-se confortáveis para experimentar, questionar e criar novas metodologias de trabalho. Visando também estimular os professores participantes do curso a se envolverem na organização do trabalho coletivo em seu ambiente escolar, buscando legitimar a educação física como componente curricular. Objetivando, principalmente, promover a sistematização de estratégias de ensino, com a finalidade de ampliar a compreensão dos fundamentos teórico/metodológicos que as sustentam, dentro da seguinte estrutura curricular: Eixos, Temas e Conteúdos. Além de planejar a prática pedagógica, numa perspectiva ampliada de formação orientada pelas dimensões produtiva, simbolizadora e social do conhecimento humano; ao longo das zonas de desenvolvimento; buscando a organização e ampliação desse conhecimento. Esse curso de extensão também se propôs auxiliar os professores na reformulação dos textos das Diretrizes Básicas de Ensino para a educação física escolar (documento que orienta a prática pedagógica na Rede Municipal de Ensino), no sentido de incorporar as modificações que foram feitas nos eixos temáticos, os quais foram revisitados nesse percurso dos cursos de extensão aqui descritos.

Dando seguimento ao curso de extensão desenvolvemos um projeto intitulado: "Educação Física Escolar: os conteúdos de ensino e sua relação com o processo de aprender", visando promover a vivência e sistematização de procedimentos metodológicos buscando estabelecer uma relação dialética com os objetivos de ensino e com uma compreensão do processo de aprendizagem/apropriação dos saberes pelos alunos. Com o objetivo de:

1. Aprofundar o estudo das bases estruturantes do projeto político pedagógico da área de educação física, pautadas nos princípios ético políticos da prática docente elaborados pelo coletivo de professores, tendo o cotidiano escolar como ponto de partida e o professor como autor de sua prática pedagógica; 
2. Promover a vivência e sistematização de procedimentos metodológicos buscando estabelecer uma relação dialética com os objetivos de ensino e com uma compreensão do processo de aprendizagem/apropriação dos saberes pelos alunos;

3. Aprofundar o estudo dos conteúdos de ensino, organizados em cinco categorias: elementos constitutivos, conceitualização, formas de organização e institucionalização, classificação e categorização e contextualização sócio política.

Além destes objetivos, nesse curso de extensão consolidamos o sentido e significado dos elementos da estrutura curricular que vimos trabalhando com os professores da Rede Municipal os quais são: Eixos/Temas/Conteúdos. Estrutura esta elaborada no contexto do planejamento coletivo e que exige outra forma de organização do conhecimento a ser ensinado, uma vez que se difere das propostas que encontramos em diferentes contextos. A sistematização dessa matriz curricular encontra-se num documento editado ao final do curso de extensão, denominado: Curso de Extensão em Educação Física Escolar: os conteúdos de ensino e sua relação com o processo de aprender; no qual o grupo composto por cerca de 30 de professores assumiu o compromisso de pensar a organização do conhecimento para todas as zonas de desenvolvimento, a partir de um tema de ensino. Esta tarefa desenvolvida em grupos de trabalho, formados por professores que atuam nas diferentes etapas do processo de escolarização, possibilitou uma troca de experiências no momento de definir os conteúdos e recursos metodológicos, refletindo sobre o processo de aprendizagem e elaborando objetivos para cada conteúdo, com a finalidade de tornar possível visualizar a continuidade e ampliação do conhecimento de um ano para o outro, ou de uma zona de desenvolvimento para outra.

Tradicionalmente, na educação física escolar, os conteúdos são identificados como sendo as próprias práticas corporais, ou ainda, mais recentemente, conhecidos por meio da expressão "temas da cultura corporal" (BRACHT, et al., 1992). Ressaltamos que por ora, a partir dos estudos que realizamos durante esses cursos e da interpretação que os professores fizeram de suas práticas pedagógicas cotidianas à luz do referencial teórico que utilizamos, trabalhamos com a seguinte interpretação:

Eixos Temáticos passaram a significar para nós, determinados contextos da vida social, cujas práticas sociais, ali agrupadas, implicam a incorporação de conhecimentos advindos de diversas áreas, representando campos de conhecimento que agrupam produções culturais que podem ser identificadas como o objeto de ensino na educação física escolar. Esses eixos estão subdivididos em cinco, a saber: 
Eixo 1 - Educação Física: tem a Escola e a Educação Física como temas a serem abordados da educação infantil ao $9^{\circ}$ ano do ensino fundamental (a Rede Municipal engloba somente estas etapas da escolarização). Deve apreciar tanto conhecimentos sobre a instituição escola quanto do componente curricular educação física no cenário da educação formal em nossa sociedade, apontando e justificando a educação física como conhecimento a ser ensinado na escola, bem como a contribuição da escola e da educação física no processo de formação humana, cooperando em primeira instância para a justificativa e valorização desta última, no contexto escolar.

Eixo 2 - Manifestações Corporais compreende o estudo sobre as manifestações corporais tradicionalmente atribuídas como objeto a ser ensinado na escola pela disciplina educação física, cujos elementos constitutivos são reconhecidos socialmente e estão inseridas na realidade a partir de características comuns como: possuir gestos e técnicas próprias, regras, locais, vestuários, equipamentos predefinidos. Busca a identificação, experimentação e reflexão sobre estas manifestações, com a finalidade de compreender suas relações com os aspectos históricos, políticos e com a formação humana, apontando a possibilidade de elaboração, reconstrução e permanente reinvenção das mesmas, de maneira crítica e coletiva.

Eixo 3 - Corporeidade Humana contempla o conhecimento sobre o corpo, em suas diferentes dimensões, como elemento constitutivo da existência humana, relacionando os estudos existentes sobre a concepção da corporeidade humana com o agir social, levando em conta os modismos e influências da mídia na construção de uma visão de corpo nos contextos histórico e culturais. Os temas de ensino, neste eixo, devem tratar o corpo a partir de uma perspectiva estética, histórica e social, para além do conhecimento biológico, com a finalidade de romper com a visão fragmentada "corpo/mente" que, historicamente, predominou na área da educação física.

Eixo 4 - Lazer na educação física escolar deve contemplar o estudo sobre as manifestações corporais que podem ser materializadas no tempo do não trabalho. Abordando aspectos do conhecimento que permitam compreender as implicações do desenvolvimento tecnológico no campo do lazer, as diferentes possibilidades de práticas de lazer, identificando os locais e equipamentos de lazer, bem como a relação entre o público e o privado no âmbito do lazer como direito social. A discussão sobre estes temas deve nos remeter também ao estudo das diferentes práticas sociais levando em consideração os aspectos políticos, sociais, econômicos e da formação humana. 
Eixo 5 - Atividade Física/Qualidade de Vida se caracteriza pelo estudo da atividade física em suas diferentes possibilidades e limites de materialização na vida social, compreendendo-a como uma construção histórica que se fundamenta no conhecimento advindo das ciências naturais, atendendo a interesses políticos, sociais e econômicos. Considera-se, ainda, para a reflexão neste eixo, as múltiplas relações entre atividade física e qualidade de vida, nos remetendo ao campo da saúde, especialmente pela visão tradicionalmente presente nesse, e de uma possível relação de causa e efeito entre ambas. Neste sentido, torna-se fundamental que, na escola, os alunos sejam conduzidos à uma compreensão dos aspectos que definem qualidade de vida em diferentes contextos histórico culturais e socioeconômicos, pois trata-se de um conceito que deve ser justificado por critérios definidos a partir das condições concretas da vida social.

Os Temas de Ensino são as produções culturais, práticas sociais, fenômenos ou atividades humanas que podem e devem ser reconhecidas, compreendidas e problematizadas nas aulas de Educação Física, de acordo com a concepção de educação que nos orienta, sendo, portanto, agrupadas em Eixos Temáticos, expressando, assim, a leitura da realidade, justificada com base no projeto político pedagógico da área.

$\mathrm{Na}$ atual estrutura curricular são apresentados os seguintes temas de ensino, distribuídos nos eixos temáticos: Educação Física: A Escola e A educação Física como componente curricular; Manifestações Corporais: Esporte, Jogos, Ginástica, Danças, Lutas, Brincadeiras de Rua, Teatro, Capoeira, Circo e Jogos Olímpicos; Corporeidade Humana: Órgãos dos sentidos, Produção Midiática, Mundo do Fitness, Corpo e Indústria da Moda; Lazer: Racha/pelada, Ruas de Lazer, Colônia de Férias, Jogos Eletrônicos, Atividades de "aventura" e Políticas públicas do lazer; Atividade Física e Qualidade de Vida: Alimentação, Aspectos biológicos, Exercício Físico, Patologias associadas ao exercício físico e Fisioterapia desportiva.

Vale ressaltar que a organização dos temas não é estática, permitindo sua mobilidade entre os eixos, dependendo dos objetivos de ensino, sendo possível, também a criação de novos temas advindos da realidade cultural. Além disso, os aspectos atribuídos aos conteúdos de ensino são comuns aos diversos temas, pois apontam o tratamento que pode ser dado ao conhecimento acerca dos mesmos.

Os Conteúdos de Ensino são aspectos do conhecimento sobre cada tema, tomados como referência para a produção de saberes escolares, os quais podem contribuir para uma compreensão crítica sobre a realidade social. Sua compreensão passou a ser entendida na 
lógica da produção de saberes escolares, sendo um processo que ocorre antes, durante e depois do ato de ensinar, do qual participam professores e alunos. Para orientar organização do conhecimento por meio dos conteúdos foram definidos cinco aspectos: 1Elementos constitutivos - descrição dos fenômenos a partir da identificação de sua materialização na realidade concreta (aparência), visando reconhecer o que, como, quem e onde; 2- Classificação/caracterização - agrupamento dos elementos da cultura tomados como objeto de estudo/ensino a partir de critérios previamente definidos, de forma a identificar os aspectos que permitem saltos qualitativos na forma de explicá-los, dependendo dos objetivos de estudo; 3- Conceitualização - processo de organização do pensamento para a produção de novas sínteses teóricas, avançando para uma compreensão mais aprofundada da realidade; 4- Contextualização sociopolítica - a relação dos temas estudados com o modelo de sociedade, as formas de interação humana e as relações de poder e 5- Institucionalização - processo por meio do qual as práticas sociais são organizadas e reorganizadas na sociedade, por meio de diferentes modelos institucionais, permeados de interesses sociais, econômicos e políticos (ANTUNES; AMARAL; LUIZ, 2008).

O diálogo que nos permitiu avançar na explicação desta estrutura curricular se deu com Saviani (2010), especificamente na discussão que ela faz das relações entre conteúdo e método de ensino. Esta relação é abordada pela autora a partir de sua aproximação com a relação currículo/didática, implicando numa compreensão dos processos de produção dos saberes escolares, e sua organização numa matriz curricular; e do processo de escolarização por meio do qual a trajetória pedagógica é desenhada à luz de uma visão sobre o desenvolvimento do aluno. Segundo ela

[...] o conteúdo do processo pedagógico refere-se, fundamentalmente, ao conjunto de conhecimentos e técnicas cuja assimilação/apropriação a escola deve propiciar aos educandos; e o método refere-se à necessária trajetória a ser percorrida para que isto seja garantido (SAVIANI, 2010, p. 10).

No exercício de produção e organização de saberes escolares, na forma de conteúdos de ensino, fica claro que deve ser dada as bases epistemológicas do conhecimento veiculado nas aulas de educação física escolar. Se na escola o que se aprende nessas aulas não se diferenciar do que o aluno encontra fora da escola, a existência ou permanência desse componente curricular na instituição escolar pode tornar-se questionável. Nossa legitimidade como matéria de ensino relaciona-se diretamente à 
epistemologia do conhecimento tratado em nossas aulas. Encontramos a confirmação dessa ideia em Saviani (2010), quando ela aponta que “[...] o saber escolar deve aproximar-se do saber científico, filosófico, metódico, crítico, reflexivo, erudito, enfim, os que integram o acervo cultural organizado, sendo estes, objeto de conversão pedagógica” (p. 147).

A direção político pedagógica materializa-se no processo de aprender, o qual se expressa na forma como o conhecimento é organizado ao longo do processo de escolarização e nos princípios pedagógicos para a seleção de recursos metodológicos e procedimentos de ensino. Esses revelam a concepção de formação humana com a qual se pretende operar, se para a conformação com o modelo social vigente ou para a emancipação humana. Por isso, fez e faz todo sentido empreender estudos acerca da relação conteúdo/método, se desejamos construir um ensino de educação física escolar numa perspectiva crítica.

\section{Algumas considerações}

Esta iniciativa, desenvolvida no âmbito do projeto de extensão, se junta a outras ações que já foram e/ou estão sendo desenvolvidas por professores das Universidades com a finalidade de ampliar os espaços de formação continuada, bem como as alternativas para o envolvimento e a organização coletiva dos profissionais das escolas públicas, na busca da transformação da prática educativa.

Nesse sentido, este projeto pretende tornar-se uma alternativa para estimular o envolvimento e a organização coletiva de professores de educação física das escolas públicas, minimizando algumas das dificuldades que têm impedido e/ou limitado o avanço de projetos políticos comprometidos com uma concepção crítica de educação. "Outro aspecto que vale destacar é que a busca de atualização/adequação dos processos de ensino, neste diálogo prática/teoria/prática impulsiona os professores a participar da formação continuada e dos espaços de produção coletiva" (AMARAL, et al., 2009, p. 13).

Portanto, o que apresentamos como proposta para a educação física escolar resulta não de uma apropriação linear da teoria ou, de uma possível "aplicação" da mesma, mas do que tem sido possível desenvolver por meio do confronto com a realidade. Por este motivo, é necessário reafirmar o entendimento de que

[...] o professor não deve aplicar teoria na prática, e sim, (re)construir (reinventar) sua prática com referência em ações/experiências e em reflexões/teorias. É fundamental que esta apropriação de teorias se dê de 
forma autônoma e crítica, portanto, como ação de um sujeito, de um autor (CAPARRÓZ; BRACHT, 2007, p. 27).

Desta maneira, ao se optar por um tipo de metodologia que coloque em evidência o que o professor já faz, ou consegue fazer, estamos procurando, ao mesmo tempo, compreender a realidade, contextualizando-a e, também, produzindo ações que possam ser desencadeadas a partir desta mesma prática de sujeitos concretos, que resultem em mudanças significativas. Buscando "[...] a valorização do cotidiano e da prática dos professores como espaço de construção de saberes" (CAPARRÓZ; PIROLO; TERRA, 2004, p. 157).

Entendemos que as discussões sobre organização curricular devem resultar de uma permanente reflexão sobre a realidade escolar, sistematizada nos estudos realizados na formação continuada, visando sua reformulação sempre que avanços teórico/práticos são alcançados. Soares et al. (2012) justificam que a função social do currículo é ordenar a reflexão pedagógica dos estudantes de maneira que eles possam, por meio de uma lógica de pensamento dialética pensar a realidade social. Já que a escola não produz o conhecimento científico, ela deve apropriar-se dele dando tratamento metodológico de modo a facilitar a apreensão pelos estudantes. A escola fica então, com a tarefa de desenvolver a reflexão pedagógica sobre esse conhecimento. Os autores ainda sinalizam um caminho possível para o desenvolvimento desta reflexão, "Para desenvolvê-la, apropria-se do conhecimento científico, confrontando-o com o saber que traz do seu cotidiano e de outras referências do pensamento humano: a ideologia, as atividades dos alunos, as relações sociais, entre outras" (SOARES et al., 2012, p. 29).

Finalmente, vale destacar que neste processo permanente de busca de alternativas curriculares, é fundamental reconhecer a autoria dos professores e sua autonomia político/pedagógica na produção do currículo. Pois, dessa forma, estaremos contribuindo para aquilo que foi proposto por Caparróz; Pirolo; Terra (2004) em relação à formação de professores em educação numa perspectiva crítico reflexiva, “ [...] que os professores se encontrem e se vejam nas descrições de suas experiências, de suas realidades e de suas práticas político-pedagógicas" (p. 160).

Ressaltamos que, do ponto de vista dos professores envolvidos, as produções coletivas representam um importante avanço em sua prática docente, conforme pode ser constatado nas avaliações realizadas repetidamente ao final de cada curso de extensão. Entretanto, ainda há caminhos a percorrer no sentido de alcançar o grande contingente de 
professores da Rede Municipal que não participam da formação continuada. Porém, como os caminhos não estão prontos, exigem o compromisso do engajamento e da disposição para o trabalho coletivo, ainda distante da realidade de muitas escolas municipais, nas quais muitos problemas, dificuldades e limitações veem sendo enfrentadas. Mas, considerando os limites desta publicação, deixaremos a reflexão sobre os desafios políticos de um trabalho de formação continuada no espaço público para outro momento.

\section{Referências}

AMARAL, G. A. do. Planejamento de Currículo na Educação Física: possibilidades de um projeto coletivo para as escolas públicas de Uberlândia/MG. 2003. 193f. Dissertação (Mestrado em Educação) - Programa de Pós-Graduação, Pontifícia Universidade Católica, São Paulo, 2003.

AMARAL, G. A. et al. Pressupostos da Educação Física Escolar: Aproximação a uma Síntese Teórico/Metodológica. In: XVI CONGRESSO BRASILEIRO DE CIÊNCIAS DO ESPORTE E III CONGRESSO INTERNACIONAL DE CIÊNCIAS DO ESPORTE, 2009, Salvador. Anais. Salvador: XVI CONBRACE e III CONICE, 2009.

ANTUNES, M. F. de S.; AMARAL, G. A.; LUIZ, A. R. Proposta Curricular para a Educação Física: uma experiência a partir da formação continuada. Motrivivência: Revista de Educação Física, Esporte e Lazer, ano XX, n. 31, p. 143-162, dez. 2008.

ARANHA, M. L. de A. Filosofia da Educação. São Paulo: Moderna, 2006.

BRACHT, V; et al. Metodologia do ensino da educação física. São Paulo: Cortez, 1992.

CAPARROZ, F. E. Discurso e prática pedagógica: elementos para a compreensão da complexa teia que envolve a educação física na dinâmica escolar. In: CAPARROZ, F. E (Org.) Educação Física Escolar: política, investigação e intervenção. Vitória: Proteoria, 2001, v. 1, p.193-214.

CAPARRÓZ, F. E.; PIROLO, A. L.; TERRA, D. V. A relação entre professores e pesquisadores na construção do saber. In: CAPARRÓZ, F. E.; ANDRADE FILHO, N. F. de. (Org.). Educação física escolar: política, investigação e intervenção. Vitória: UFES, LESEF: Uberlândia: UFU, NEPECC, 2004, v. 2, p. 155 - 183.

CAPARROZ, F. E.; BRACHT, V. O tempo e o lugar de uma didática da educação física. Revista Brasileira de Ciências do Esporte, Campinas, v.28, n.2, p.21-38, jan. 2007.

KUNZ, E. Transformação didático-pedagógica do esporte. Ijuí: Unijuí, 2001a.

KUNZ, E. Fundamentos normativos para as mudanças no pensamento pedagógico em Educação Física no Brasil. IN: CAPARRÓZ, F. E. (Org.) Educação Física Escolar: Política, Investigação e Intervenção. Vitória: Proteoria, 2001b, v. 1, p. 53-74.

MOLINA NETO, V., MOLINA, R. M. K. Identidade e Perspectivas da Educação Física na América do Sul: Formação Profissional em Educação Física no Brasil. In: BRACHT, V.; CRISORIO, R. (Org.). A Educação Física no Brasil e na Argentina. Campinas, SP: Autores Associados, 2003, p. 259-278. 
SAVIANI, N. Saber escolar, currículo e didática: problemas da unidade conteúdo/método no processo pedagógico. 6ed. Campinas: Autores Associados, 2010.

SCHNEIDER, M. S. P. da S. O planejamento de aula em dois contextos: do institucional ao colaborativo. 2000. 189f. Dissertação (Mestrado em Educação)- Programa de Pós Graduação em Educação, Pontifícia Universidade Católica, São Paulo, 2000.

SEVERINO, A. J. Filosofia. São Paulo: Cortez, 2007.

SEVERINO, A. J. Educação, sujeito e história. São Paulo: Olho d'Água, 2009.

SOARES, C. L et al. Metodologia do ensino de educação física. São Paulo: Cortez, 2012.

ROCHA, M. S. P. de M. L. da. Não brinco mais: a (des)construção do brincar no cotidiano educacional. Ijuí, Unijuí, 2005.

RECEBIDO EM: 20/09/2013.

APROVADO EM: 23/02/2016. 